This is a postprint version of the following published document:

Farahbakhsh, R., Cuevas, A., Cuevas, R., Rejaie, R., Kryczka, M., Gonzalez, R. \& Crespi, N. (2013). Investigating the reaction of BitTorrent content publishers to antipiracy actions. 13-th IEEE International Conference on Peer-to-Peer Computing IEEE P2P 2013. Trento, Italy, September 9-11, 2013: Proceedings.

DOI: $10.1109 /$ P2P.2013.6688699

(C) 2013 IEEE. Personal use of this material is permitted. Permission from IEEE must be obtained for all other users, including reprinting/ republishing this material for advertising or promotional purposes, creating new collective works for resale or redistribution to servers or lists, or reuse of any copyrighted components of this work in other works 


\title{
Investigating the Reaction of BitTorrent Content Publishers to Antipiracy Actions
}

\author{
Reza Farahbakhsh*, Ángel Cuevas ${ }^{\dagger *}$, Rubén Cuevas ${ }^{\dagger}$, Reza Rejaie $^{\ddagger}$, \\ Michal Kryczka ${ }^{\S}$, Roberto Gonzalez ${ }^{\dagger}$ and Noel Crespi* \\ * Institut-Mines Télécom, Télécom SudParis, \{reza.farahbakhsh, noel.crespi\}@it-sudparis.eu \\ $\dagger$ Universidad Carlos III de Madrid \{acrumin, rcuevas, rgonza1\}@it.uc3m.es \\ $\ddagger$ University of Oregon $\{$ reza@cs.uoregon.edu\} \\ $\S$ Institute IMDEA Networks \{michal.kryczka@imdea.org\}
}

During recent years, a few countries have put in place online antipiracy laws and there has been some major enforcement actions against violators. This raises the question that to what extent antipiracy actions have been effective in deterring online piracy? This is a challenging issue to explore because of the difficulty to capture user behavior, and to identify the subtle effect of various underlying (and potentially opposing) causes. In this paper, we tackle this question by examining the impact of two major antipiracy actions, the closure of Megaupload and the implementation of the

French antipiracy law, on publishers in the largest BitTorrent portal who are major providers of copyrighted content online. We capture snapshots of BitTorrent publishers at proper times relative to the targeted antipiracy event and use the trends in the number and the level of activity of these publishers to assess their reaction to these events. Our investigation illustrates the importance of examining the impact of antipiracy events on different groups of publishers and provides valuable insights on the effect of selected major antipiracy actions on publishers' behavior.

Piracy, law, Cyberlocker, Megaupload, P2P, BitTorrent, Hadopi.

\section{INTRODUCTION}

During the past decade, the Internet has witnessed an increasing level of online piracy of copyrighted content. In particular, Peer-to-Peer content distribution applications (e.g. BitTorrent, Gnutella) and Cyberlocker services (e.g., Megaupload) have facilitated illegal sharing of copyrighted content ${ }^{1}$. At the same time, the availability of copyrighted content by these systems at no cost, has led to an explosion in their popularity and therefore to their contribution in overall Internet traffic. While legal actions were taken against few major and many minor violators who illegally published, consumed or facilitated the distribution of copyrighted content, online piracy appears to become even more widespread in different countries. In recent years, these trends have prompted copyright holders to demand the legislation and implementation of more effective online antipiracy laws in several countries. However, such an effort has faced strong opposition by various stake holders in several countries. In fact, we are only aware of a small number of countries that have legislated and implemented an online antipiracy law. Given the difficulty to put in place an online antipiracy law, an interesting question is "whether and to what extent an antipiracy law and its associated enforcement actions can affect the behavior of violating users?"
This intriguing question is very difficult to answer for at least three reasons as follows: First, the effect of an antipiracy event (e.g., publicizing relevant laws or enforcement actions) can be assessed on different groups of users including those who publish or consume copyrighted content, users with different levels of involvement (as publisher or consumer), or users for a specific system or in a particular country. Clearly, the impact of an antipiracy event could vary significantly across different groups. Second, there could be other (potentially some unknown) co-existing social, economical, and technical factors that have a dominant and possibly opposing effect on piracy behavior among users. More importantly, it is very challenging to identify and capture all the relevant major factors, and assess their level of impact on piracy behavior among users. For example, the drop in the number of online pirating for movies in the the US could be due to a combination of antipiracy actions against a few users and/or due to user access to cheap and legal content via Netflix. Furthermore, the effect of an antipiracy action could be short- or long-lived. Third, there is no ground-truth to reliably validate any finding about user reactions to antipiracy events. A survey of users can be conducted to obtain a more accurate view of the behavior for a relatively small group of users (e.g., few thousands). However, only a small fraction of surveyed users may be involved in antipiracy and those users may not indicate their intention because of any concern for legal action against them.

Despite these challenges, a few recent studies have examined the effect of specific antipiracy actions on the behavior of a particular group of users (i.e.consumers) in a single country using measurement [1], or survey of users [2] or businesses [3]. All these studies presented a collection of evidences to illustrate that the enforcement of local antipiracy laws succeeded in reducing the downloading activity of copyrighted content among their target group of consumers. To our knowledge, the effect of antipiracy actions on content publishers have not been

\footnotetext{
${ }^{1}$ We want to make clear that Peer-to-Peer technology as well as Cyberlocker facilities can be used for many other purposes further than sharing copyrighted material. Furthermore, when we refer to illegal activity in this paper we are not offering our opinion but just relaying on the fact that there are court sentences and open processes using this term related to publishers of copyrighted content. This paper does not include the opinion of the authors regarding whether sharing copyrighted content is a legitimate action or not.
} 
examined, and it is essential because they feed the ecosystem of online piracy and in some cases gain substantial profit [4].

In this paper, we investigate the effect of antipiracy actions on the publishers of copyrighted content. To cope with the challenges in tackling such a broad question, we limit the scope of our study in two ways as follows: First, we only examine the effect of two major antipiracy actions: $(i)$ the closure of Megaupload was a sudden event that was publicized worldwide, and (ii) the French antipiracy law (Hadopi law) that was debated, legislated and fully implemented over a two year period. We intuitively expect these antipiracy actions to have a dominating impact on the behavior of their corresponding group of users. Therefore, any potential error in our analysis due to potentially unknown factors should be relatively small. Second, we only consider the effect of these two antipiracy actions on the content publishers in the largest BitTorrent portal, namely the The Pirate Bay (TPB). Since a significant majority of BitTorrent publishers upload copyrighted material [5][6], they provide a large population of publishers that are actively engaged in online piracy and therefore their reactions offer relevant and meaningful insights for this study.

One key contribution of this paper is our methodology to leverage the reaction of BitTorrent publishers for assessing the effect of selected antipiracy actions. Toward this end, we capture snapshots of all BitTorrent publishers along with their uploaded (and downloaded) files through TPB. The timing of our snapshots are properly aligned to the target antipiracy actions to increase the likelihood of detecting any measurable effect even if its impact is short-lived. We use the changes in the daily number of relevant BitTorrent publishers and their contribution over the proper time frame as our basic metrics to assess the effect of each antipiracy action. We show that this basic metric does not always paint a clear picture of publisher behavior. Therefore, we deepen our analysis by grouping publishers based on different criteria to identify the most likely cause of the observed changes in publishers' behaviour. These criteria include: $(i)$ level of activity (e.g., active vs casual publishers), (ii) publishers' business profile (e.g., profit-driven vs altruistic) or (iii) monitoring policies of their hosting facilities (soft vs strict). Finally, we corroborate our findings with a few independent sources including Google trends and other reports to gain more confidence. While there is not ground truth to validate our findings, we believe that the number of discovered evidences and their temporal alignment offer a very convincing explanation for how these selected antipiracy actions have influenced the behavior of BitTorrent publishers.

The second key contribution of this paper is to demonstrate some of the subtleties in identifying the potential effect of an antipiracy action, and properly relating them to their cause. These findings of our "detective work" are summarized as follows:

The closure of Megaupload: Many publishers joined BitTorrent most likely from Megaupload (and other Cyberlockers) right after its closure. This resulted in an increase in the overall number of TPB publishers but, surprisingly, had no impact on their overall publishing rate. This is due to the fact that major BitTorrent publishers that maintain a private BitTorrent portal (i.e. a similar business to a Cyberlocker) reduced their publishing rate in reaction to this event.

French antipiracy Law: The French population have followed the legislation and implementation of the 3 strike law that targets both consumers and publishers on any copyrighted content through P2P applications. We show that the first two steps of the Hadopi law have been very effective in decreasing the number of casual publishers that as we demonstrate, are indeed active consumers. However, the number of active publishers (i.e. uploading more than one content per day on average) remained stable and they considerably increased their publishing rate. This reaction is surprising given the reduction of French consumers for copyrighted content through P2P applications as reported in [2] and [7]. Our closer examination revealed that most of top French publishers do not publish any French content. In fact, the concentration of these publishers in a particular hosting facility in France (called $\mathrm{OVH}$ ) appears to be motivated by the absence of a strict policy for avoiding the use of BitTorrent on its servers. These professional publishers are legally savvy and realize that the opportunity to freely operate from $\mathrm{OVH}$ simply outweighs any unlikely antipiracy action as a result of the Hadopi law.

The rest of this paper is organized as follows: We briefly describe few prior work in Section II. Section III describes an overview of our data collection techniques and our datasets. In Section IV, we present our first case study on the effect of Megaupload closure. Our second case study on the effect of French antipiracy law is discussed in Section V. We conclude the paper in Section VI.

\section{RELATED WORK}

There have been several studies by behavioral scientists on the motivation of users to engage in online piracy [8], [9], [10], [11]. These studies typically rely on the collected data from a small-scale survey (a couple of hundreds user). We are only aware of two prior measurement studies on the effect of antipiracy events on illegal file sharing among Internet users.

First, Alcock et al. [1] recently analyzed the impact of the New Zealand antipiracy law on different applications. They monitored the traffic of DSL connections for 4000 users at three different time periods in 2011 and 2012. Their study demonstrates that the consumption of copyrighted material has decreased among users and concludes that this is the effect of the local antipiracy law. Similar to this study, our work relies on a collection of evidences to draw a conclusion about user behavior. However, we focus on the behavior of publishers (rather than consumers) who are clearly engaged in online piracy.

Second, Lauinger et al. [12] examined the contents of a large number of uploaded files in eight Cyberlockers to measure the impact of Megaupload closure on the availability and lifetime of copyrighted files in other Cyberlockers. They demonstrate that after Megaupload closure, other Cyberlockers proactively 


\begin{tabular}{cccc} 
& pb10 & pb11 & pb12 \\
\hline Crawling Period & $10-09-04-10-05-05$ & $11-10-21-11-12-13$ & $12-01-28-12-02-12$ \\
Duration (days) & 27 & 54 & 16 \\
Pubishers (username) & $7.1 \mathrm{~K}$ & $6.9 \mathrm{~K}$ & $3.3 \mathrm{~K}$ \\
Torrents & $38.2 \mathrm{~K}$ & $72.0 \mathrm{~K}$ & $21.0 \mathrm{~K}$ \\
Consumers & $27.3 \mathrm{M}$ & $25.6 \mathrm{M}$ & $5.1 \mathrm{M}$ \\
Downloads & $95.6 \mathrm{M}$ & $79.0 \mathrm{M}$ & $11.1 \mathrm{M}$ \\
\hline
\end{tabular}

TABLE I

DATASET DESCRIPTION

increased the filtering of copyrighted material from their servers, as had been reported in the press [13]. In addition, in the same study the authors present a qualitative discussion of the potential impact that the SOPA (US) law [14] could had achieved if it had been implemented. While this work is in spirit similar to ours, we examine the behavior of thousands of BitTorrent publishers (uploading tens of thousands of files).

We are also aware of two prior reports on the effect of the Hadopi law on French Internet consumers. Preliminary results of a longitudinal survey of $2 \mathrm{~K}$ users carried out by the Hadopi commission indicated a decrease in the download of copyrighted material [2]. In particular, $72 \%$ of the respondents to this survey who had received a warning, declared that they had decreased or stopped their activity, and 50\% of the respondent indicated that they have increased the consumption of legal copyrighted content. The second study [3] analyzed the data from iTunes record sales by four major labels and reported 25\% increase in the purchase of iTunes music among French users after the enforcement of the Hadopi law while the increase in a neighbor country such as Spain was negligible. Based on these two pieces of evidence, they concluded that the Hadopi law has been successful in deterring P2P downloads of copyrighted material.

To the best of our knowledge, our study is the first investigation of the effect of antipiracy actions on the behavior of publishers of copyrighted content that is based on measuring a large number of such publishers. More importantly, our investigation goes beyond obvious metrics and reveals the impact of other social, economical, and technical factors through data-driven analysis.

\section{Data Collection AND Datasets}

Our objective is to capture multiple snapshots of the BitTorrent ecosystem over time in order to characterize longitudinal trends in the population and activity of publishers. We use these trends to assess the impact of antipiracy events on content publishers. Towards this end, we leverage active measurement over The Pirate Bay (TPB) portal using the methodology and tools that were developed in our earlier study [4]. We focus on TPB in this study since it is the most popular BitTorrent portal as reported by scientific studies [15] and Alexa ranking [16]. In particular, TPB is one of the top-100 most popular websites in the Internet and receives at least twice (and in most cases significantly larger) daily visit than any other BitTorrent portal based on Alexa information. Furthermore, all the indexed content on TPB portal are explicitly uploaded by a publisher in contrast to the other major portals (e.g., Torrentz or IsoHunt) that use crawling techniques to identify their indexed content. These features make TPB a suitable venue to capture snapshots of the BitTorrent ecosystem and conduct our analysis. This section describes a brief overview on BitTorrent and our measurement methodology as well as the main characteristics of our collected datasets.

\section{A. Background on The Pirate Bay}

TPB is simply a rendezvous point between content publishers and consumers. When a publisher wishes to make a content available within the BitTorrent ecosystem, its first step is to generate a unique id known as the infohash and register the content with one (or multiple) tracker(s). A tracker keeps track of the IP addresses for a group of peers that concurrently participate in the delivery of a content (i.e. form a swarm). A participating peer can be of two types: peers with a complete copy of a content are known as seeders while other peers are leechers. Therefore the content publisher is the first seeder in a swarm. The second step is to advertise the content by generating a torrent file that provides metainformation for consumers including the IP address of the associated tracker(s). The publisher uploads the torrent file to TPB and possibly other BitTorrent portals. In the case of TPB, the publisher needs to be registered with the portal and uses her account (with a specific username) to advertise a content. TPB creates a separate webpage for each registered user in which all its published content along with publishing times are listed. Finally, TPB offers an RSS service where consumers can subscribe and receive a notification as soon as a new content becomes available. To download a content, a consumer typically retrieves the .torrent file from a portal, extracts the IP address of the tracker and connects to it. The tracker provides a list of IP addresses for a random subset of participating peers in the swarm to the new peer so that the new peer can connect to them and join the swarm.

\section{B. An Overview of the Measurement Methodology}

Our measurement tool can capture a rather complete snapshot of all active publishers, their published files and associated consumers within a window of time. To achieve this goal, our tool subscribes to TPB's RSS service to get a notification for any new content that is published on the 
portal $^{2}$. The RSS feed provides the torrent file along with the username of the content publisher. Our tool retrieves the IP address of the tracker from the .torrent file (or the magnet link) and immediately connects to it. By connecting to the tracker immediately after the content is published, we are able to identify the IP address of the initial seeder (i.e. the publisher's location) in many torrents. Our tool periodically connects to the tracker to retrieve the IP addresses for (typically) 200 randomly-selected participating peers (i.e. consumers) while respecting the reconnection time imposed by the tracker in order to avoid being banned. To cope with this limitation, our tool probes a tracker from eight geographically-distributed nodes in parallel and captures the IP address of a majority of consumers. We use MaxMind [17], an IP-to-geo mapping database, to determine the location of discovered publishers and consumers. In summary, our captured snapshots contain the following information for each published torrent on TPB portal: (i) publisher's username and IP address, (ii) list of IP addresses for associated consumers. Further details can be found at our prior work [4].

\section{Datasets}

Using our measurement tool, we have collected three snapshots of TPB system during the past two years. Table I summarizes the main characteristics of each snapshot including: crawling period, the number of unique publishers, consumers, torrents (i.e. published files) and downloads for the three datasets labeled as pb10, pb11 and pb12. Each dataset was collected over a sufficiently long time such that any daily or even weekly variations among users and their activities are captured. The pb11 and pb12 snapshots are captured shortly before and after the closure of Megaupload site [18]. Therefore, we use these two snapshots to examine the impact of Megaupload closure. Moreover, our pb10 and pb11 snapshots were collected 18 months apart and are used to investigate the effect of French antipiracy law on French users.

\section{EFFECT OF a Global ANTIPIRACy EVENT}

In this section, we investigate how BitTorrent publishers reacted to a major antipiracy action, the closure of Megaupload [19]. We focus on this antipiracy action against Megaupload because it was a major player in illegal sharing of copyrighted content. Megaupload was the most popular Cyberlocker website. Cyberlockers provide storage service to end users that enables them to share their online stored content with other users through a URL. They have quickly become very popular among users for sharing copyrighted material (e.g., movies, TV shows, music, etc) through their websites [20]. These websites became very profitable through posting from ads and selling premium subscriptions that provide end users with a better experience (e.g., higher download rate). Moreover, they even encouraged users to publish interesting content by

\footnotetext{
${ }^{2}$ Note that since Feb. 2012, TPB only indexes magnet links instead of .torrent files. We have accordingly updated our tool to properly operate with this new indexing strategy.
}

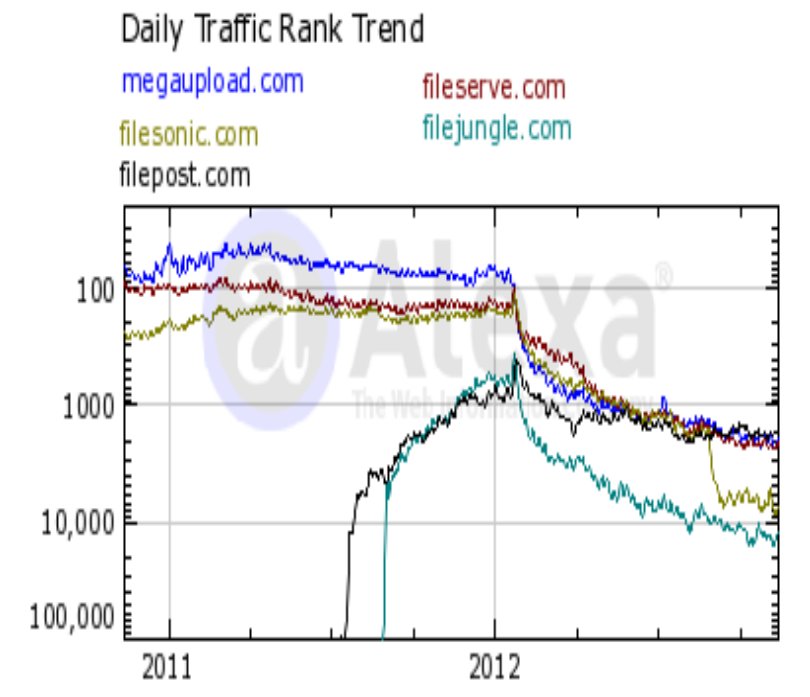

Fig. 1. Evolution of Alexa ranking for five popular Cyberlockers over the last two years (source Alexa).

offering some income to publishers whose content became popular [21]. To illustarte the popularity of Megaupload, we note that Megaupload had 180M registered users and 50M daily visitors, and stored 12 billions unique files with the aggregate size of 25 petabytes [19]. We first provide some info about Megaupload closure and then examine its impact on BitTorrent publishers.

\section{A. The Closure of Megaupload}

On January 19th 2012, the FBI (in coordination with other agencies across multiple countries) shut down Megaupload website and arrested their owners on charges of worldwide online piracy that produced $\$ 175 \mathrm{M}$ unlawful income and caused $\$ 500 \mathrm{M}$ loss for the copyright owners [22]. This antipiracy event had a worldwide coverage. To demonstrate the overall effect of this well publicized event on the Cyberlockers' ecosystem, Figure 1 presents the evolution of the Alexa ranking [16] for five popular Cyberlockers over the past two years. This figure shows two points: (i) Before Megaupload closure, all of these cyberlockers were either already among the top200 websites in Alexa ranking or their ranking was rapidly improving until the closure of Megaupload. (ii) After the closure of Megaupload, the ranking of all Cyberlockers (and thus their popularity) were rapidly and consistently dropping. This effect could be due to the adoption of new strategies by Cyberlockers to actively remove all copyrighted content as reported by a recent study [12] and in press [13]. In summary, these evidences confirm that the closure of Megaupload had a significant impact on all Cyberlockers and possibly all systems that facilitated illegal sharing of copyrighted content.

\section{B. Effect on BitTorrent Publishers Activity}

We rely on our pb11 and pb12 BitTorrent snapshots that were collected shortly before and after the closure of Megaupload. Given the short time between both snapshots and our 


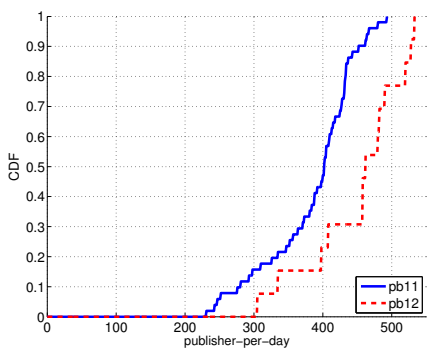

(a) CDF daily publishers

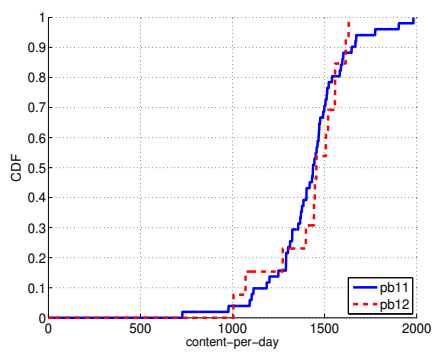

(b) CDF daily content
Fig. 2. CDF for the number of daily publishers and daily contribution in pb11 and pb12 datasets.

\begin{tabular}{ccc}
\hline & pb11 & pb12 \\
\hline Avg. daily publishers & 367 & $420(+14.4 \%)$ \\
Avg. daily contribution & 1334 & $1314(-1.5 \%)$ \\
\hline
\end{tabular}

TABLE II

Aggregate Results For PUblishing ACTIVITy IN BitTorRent. The TABLE SHOWS THE AVERAGE DAILY PUBLISHERS AND THE AVERAGE DAILY UPLOADED CONTENT IN PB11 AND PB12. THE VALUE IN PARENTHESIS INDICATES THE RELATIVE DIFFERENCE BETWEEN PB 11 AND PB 12 .

target event, and the fact that (to the best of our knowledge) no other major relevant event occurred during this period, we are confident that any change in the behavior of BitTorrent publishers is most likely triggered by the closure of Megaupload. We use two metrics to measure the effect of Megaupload closure on BitTorrent publishers as follows: (i) the average daily number of active BitTorrent publishers, and (ii) the average daily number of discovered uploaded content. Using these daily average values enables us to compare these characteristics of publishers across different datasets despite the differences in dataset durations ${ }^{3}$.

Table II presents the average daily number of publishers and uploaded files for snapshots pb11 and pb12. A more detailed view of these characteristics is provided in Figures 2(a) and 2(b) that depict the distribution of daily number of publishers and uploaded files for both snapshots, respectively. These statistics reveal that the average number of publishers increased by $14 \%$ over 1.5 months whereas their activity remained roughly unchanged. The observed increase in the number of publisher (over such a short time) is surprising and is very likely caused by the migration of publishers from Megaupload (and other Cyberlockers) to BitTorrent after the closure since we are not aware of any other event during this period that can explain such increment. To validate this observation, we take a closer look at the timing of published files by individual publishers in the pb12 dataset. To obtain this information, we have crawled the TPB page of all publishers in our pb12 dataset and captured the number of files they uploaded in each day during the 75 day window between two snapshots (2011-12-01 to 2012-02-12). We observe that

\footnotetext{
${ }^{3}$ We evaluated both metrics for different time windows in pb11 (54 days) and they remain the same independently of the used window.
}

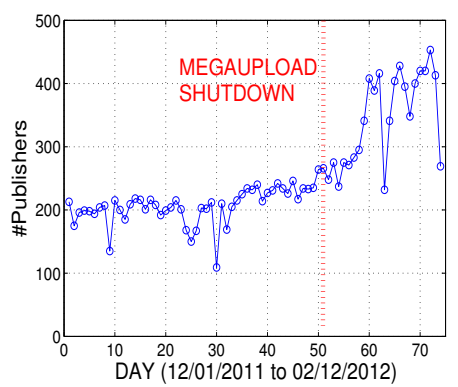

Fig. 3. Daily number of publishers among those ones collected in our pb12 snapshot during the period 2011-12-01 to 2012-02-12.

$42 \%$ of the publishers in pb12 snapshot published their first file after the closure of Megaupload which suggests that they most likely joined BitTorrent after this event. Using this information, we have also determined the aggregate number of active pb12 publishers in each day during this period as shown in Figure 3. This figure demonstrates that the number of daily publishers is relatively stable around 200 until the date of Megaupload closure and then it rapidly doubles in a few days once the implications of the event becomes clear to publishers. These evidences collectively suggest that our observed changes in the publishers' demographics and activity between pb11 and pb12 must be due to the closure of Megaupload.

1) Active vs Casual Publishers: The lack of increase in the daily number of uploads despite the clear growth in the daily number of publishers after the Megaupload closure is counterintuitive. To explain this finding, we divide the publishers in both datasets based on their average daily contribution into the following three classes: Active publishers that upload more than 10 contents per day on average, Regular publishers that upload between one and 10 contents per day, and Casual publishers that contribute less than one content per day. Table III shows the average number of publishers per day from each class and their aggregate daily contributions in snapshots pb11 and pb12. We first analyze the results for pb11 snapshot as the starting point and later discuss the evolution of each class between pb11 and pb12.

It is interesting to notice that while the number of casual publishers in pb11 is roughly three and 20 times larger than the number of regular and active publishers, respectively, the overall daily contribution of all three groups is roughly the same (between 420 to 470 files a day) before the Megaupload closure. Between pb11 and pb12, the number of casual publishers has increased by $11 \%$, while their contributions remain unchanged (less than $2 \%$ ) during this period. The number of regular publishers has increased by $23 \%$ and this has led to a roughly proportional increase $(17 \%)$ in their daily contribution. Finally, the number of active publishers grew by roughly $8 \%$ but their contribution dropped by $21 \%$. In addition, $42 \%$ of casual, $15 \%$ of regular and $6 \%$ of active publishers in pb12 are newcomers who joined BitTorrent during this period.

In summary, most of the newly arriving BitTorrent publishers after Megaupload closure are casual or regular publishers. 


\begin{tabular}{cccc} 
n=Avg. content/day & Active $(\mathbf{n} \geq \mathbf{1 0})$ & Regular $(\mathbf{1} \leq \mathbf{n}<\mathbf{1 0})$ & Casual $(\mathbf{n}<\mathbf{1})$ \\
\hline Avg. daily publishers pb11 & 13.6 & 92.4 & 261 \\
Avg. daily publishers pb12 & 14.7 & 113.8 & 291.5 \\
Avg. daily publishers difference & $+1.1(+8.1 \%)$ & $+21.4(+23.1 \%)$ & $+30.5(+11.3 \%)$ \\
\% new publishers in pb12 after Megauplaod & $6.25 \%$ & $15.23 \%$ & $42 \%$ \\
Avg. daily contribution pb11 & 471 & 423 & 440 \\
Avg. daily contribution pb12 & 374 & 510 & 431 \\
Avg. daily contribution difference & $-97(-21 \%)$ & $+87(+17 \%)$ & $-9(-2 \%)$ \\
\hline
\end{tabular}

TABLE III

NUMBER OF PUBLISHERS AND DAILY CONTRIBUTION FOR NEXT GROUPS OF PUBLISHERS CLASSIFIED BASED ON THEIR CONTRIBUTION TO THE SYSTEM. ACTIVE PUBLISHERS $(\mathrm{N} \geq 10$ CONTENT/DAY, REGULAR PUBLISHERS $(1 \leq \mathrm{N}<10$ CONTENT/DAY), AND CASUAL PUBLISHERS $(\mathrm{N}<1$ CONTENT/DAY)

\begin{tabular}{|c|c|c|c|c|c|c|}
\hline username & pb11 day cont. & pb11 rank & pb12 day cont. & pb12 rank & Business & URL \\
\hline scenebalance & 107.17 & 1 & $31.06(-71 \%)$ & 4 & BT Private Portal & www.scenetime.com \\
\hline TvTeam & 80.9 & 2 & $65.94(-18 \%)$ & 1 & BT Private Portal & www.torrentday.com \\
\hline exmnova & 58.38 & 3 & $35.38(-39 \%)$ & 3 & BT Private Portal & www.69bits.com \\
\hline sceneline & 53 & 4 & $29.93(-43 \%)$ & 5 & BT Private Portal & www.speed.cd \\
\hline chkm8te & 33.96 & 5 & $59.5(+75 \%)$ & 2 & Promoting Website & www.4ufrom.me \\
\hline UltraTorrents & 24 & 6 & $6.12(-74 \%)$ & 26 & BT Private Portal & www.ultratorrents.com \\
\hline FluxXxu & 16.46 & 7 & $19.6(+19 \%)$ & 7 & Promoting Website & www.starpix.us \\
\hline RockSaltS & 15.13 & 8 & $6.68(-55 \%)$ & 24 & Promoting Website & http://jolypic.com/ \\
\hline adultvideotorrents & 13.06 & 9 & $2.375(-82 \%)$ & 92 & BT Private Portal & www.adultvideotorrents.com \\
\hline .BONE. & 12.11 & 10 & $5.25(-56 \%)$ & 35 & Altruistic & \\
\hline Black1000 & 11.98 & 11 & OUT & OUT & Altruistic & \\
\hline MirrorRu & 11,65 & 12 & OUT & OUT & Fake & \\
\hline bigbluesea & 11.63 & 13 & OUT & OUT & Altruistic & \\
\hline eztv & 11.39 & 14 & $8(-29 \%)$ & 18 & BT Private Portal & http://eztv.it/ \\
\hline scene4all & 10.29 & 15 & $10.56(+2.56 \%)$ & 13 & Altruistic & \\
\hline
\end{tabular}

TABLE IV

A SUMMARY OF MAIN CHARACTERISTICS (DAILY CONTRIBUTION RATE AND BUSINESS PROFILE) OF THE 15 ACTIVE BITTORRENT PUBLISHERS IN PB 11 AND THE CHANGES IN THEIR LEVEL OF PUBLISHING BETWEEN PB11 AND PB 12.

The overall contribution of three groups were rather balanced before the Megaupload closure. However, after the closure, the increase in the contribution of regular publishers is roughly the same as the decrease in the contribution of active publishers which led to the unchanged overall rate between two snapshots. This raises the question that "why the relatively small number of very active publishers have dropped their publishing rate after the Megaupload closure?" Next, we tackle this question.

2) Business Profile of Active Publishers: The active publishers that upload more than 10 files a day are in most of the cases professional publishers behind profitable websites as we have demonstrated in [4]. Therefore, their wide spread reaction to (measurably) lower their contributions right after the Megaupload closure must be related to this event. To explore this issue, we employ a similar methodology to the one used in [4] to determine the business profile of all 15 active publishers in pb11. The basic idea in this methodology is to download a few published files by a publisher and manually inspect whether, where and how a consumer might be redirected to another web site associated with the publisher. This methodology broadly divides publisher profiles into the following categories: (i) BitTorrent Private Portals are associated with private trackers that offer a better experience to BitTorrent users for a seeding ratio or a fee. (ii) Promoting
Websites basically publish content for the sole purpose of attracting users to their web sites that are often hosting images services. (iii) Fake Publishers are either antipiracy agencies or malicious users that inject fake (non-existent) content in order to warn users of downloading copyrighted material or infect their computers, respectively. Altruistic Publishers simply publish content to share with others without any expectation of direct gain.

Table IV shows the following information for the 15 Active publishers in pb11 in different columns: their usernames, daily publishing rate, rank in pb11 and pb12, their business profile and the URL to their web site (if applicable). Note that the Top five publishers in pb11 and pb12 are the same. Among Active publishers, seven of them are private BitTorrent portals, three of them are promoting web sites, four are altruistic publishers, and 1 is fake. The fake accounts are quickly removed by TPB and two of the altruistic users have also removed their accounts from TPB. Interestingly, all seven private portals have significantly reduced their publishing rate (i.e. their aggregate publishing rate dropped to half from 347 to 178 files per day) whereas other groups of publishers show mixed reactions.

\section{A plausible explanation for the consistent reaction among}

\footnotetext{
${ }^{4}$ Our goal in providing the identity of these publisher is to demonstrate the fact that many of these publishers are indeed real companies.
} 


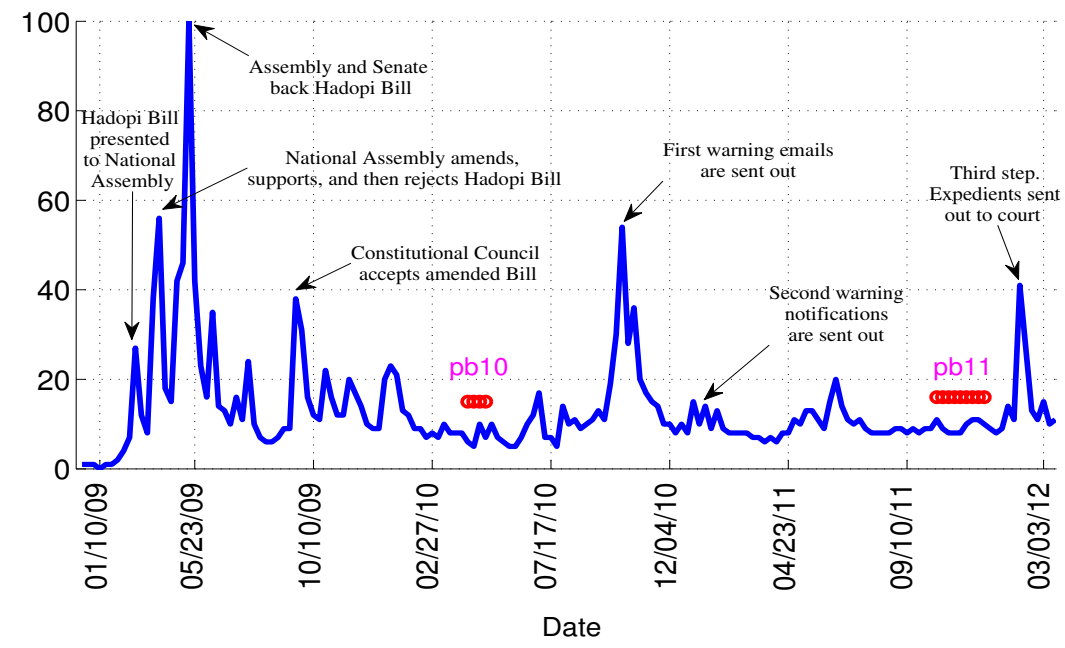

Fig. 4. Volume search in France of the keyword Hadopi during the period Jan. 2009 to Feb. 2012 according to Google Trends. In addition, we describe the events associated with major searching peaks.

publishers who manage a BitTorrent private portal is as follows: since the main business model of private portals is very similar to Megaupload (i.e. facilitating access to copyrighted material), they decreased their visibility (i.e. footprint) in the BitTorrent ecosystem to not be viewed as a major player in order to reduce the likelihood of any antipiracy action against them. This reaction is actually similar to the one observed in several Cyberlockers that tried to reduce the availability of copyrighted content in their portals [13]. Such a behavior seems to be aligned with the theory in Economics that punishing a player who performs a non-legitimate activity generates negative incentive for other players involved in similar activities [23], [24]. Finally, it is interesting to note that provided disclaimers in some of the active publishers' website confirm that they are clearly aware of copyright infringement and use the disclaimers to protect themselves against any potential legal action ${ }^{5}$.

\section{EFFECT OF A LOCAL ANTIPIRACY LAW}

In this section, we investigate the effect of a local antipiracy law in a single country, namely France, on content publishers that illegally share copyrighted material through BitTorrent. Toward this end, first we briefly justify our focus on France and provide the required background on the French antipiracy law, called the Hadopi law [25]. Afterwards, we examine the longitudinal trend among publishers as the law was legislated, approved and implemented.

To limit the number of unknown variables on our investigation, we focus on a country that has a publicized and properly enforced an antipiracy law. We note that several

\footnotetext{
${ }^{5}$ An example of such disclaimers is the following: "None of the files shown here are actually hosted on this server. The links are provided solely by this site's users. The administrator of this site (www.69bits.net) cannot be held responsible for what its users post, or any other actions of its users. You may not use this site to distribute or download any material when you do not have the legal rights to do so. It is your own responsibility to adhere to these terms".
}

western countries have had unsuccessful legislative efforts to pass a major antipiracy law. For example, the SOPA law in the US triggered the largest Internet "strike" and was tabled [14], [26]. The Digital Economy Act in the UK [27] has also been delayed till 2014 after the appeal by major ISPs such as British Telecom [28]. The Sinde law in Spain [29] is going to be ineffective even if it is implemented due to its bureaucratic process for suing a potential copyright infringing website [30]. In contrast, there are few countries such as France, New Zealand [31][1], Korea [32] or Japan [33] that have passed and implemented antipiracy laws that have been reported to be (at least partially) successful. Any of these countries offer a good example for investigating the effect of such a law. However, we focus on France primarily because French publishers have a large contribution in pb10, namely $10 \%$ of the uploaded content, in the BitTorrent ecosystem while the contribution of publishers from New Zealand, Japan or Korea is significantly smaller $(<1 \%)$. Finally, we are neither aware of any popular competing technology for legal and cheap delivery of copyrighted material to users in France (such as Netflix[34] in the US), nor other antipiracy event happening in France that could affect the outcome of our analysis.

Operation of the Hadopi Law: The Hadopi law targets users that share copyrighted content (i.e. both consumers and publishers) in Peer-to-Peer (P2P) applications among which BitTorrent is the most popular one. It is a 3-strikes law that is implemented as follows: (i) P2P users sharing copyrighted material are identified by their ISPs and receive a warning email to stop their illegal activity. (ii) The ISP of the notified users continues to monitor their activity and if they repeat their violation during the next 6 months, they will receive a $2^{\text {nd }}$ warning email together with a certified letter. (iii) The ISPs continue to monitor the notified users for one more year and if they repeat their violation, the Hadopi commission may send the violating users to the court. At this stage, a judge will determine the proper sanction that can be a fine up to 


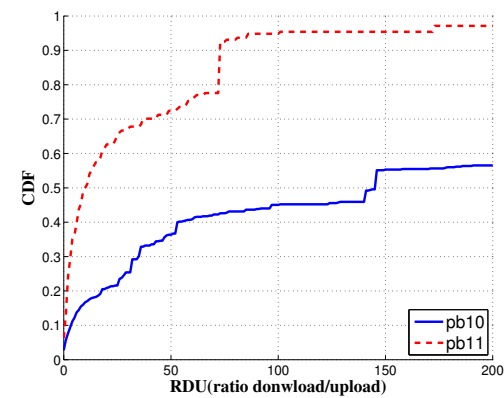

Fig. 5. Ratio download/upload $(R D U)$ for casual publishers in France.

$1500 €$ and/or the shutdown of their Internet connection for a period no longer than one month. Further details of the law can be found in [2][3].

History of the Hadopi Law: The Hadopi bill was first presented to the French Senate on June 18th 2008. After a long discussion in the French Assembly and Senate, the law was amended and passed on June 2009. The last legal step took place on October $22^{\text {nd }} 2009$ when the Constitutional Council finally approved the law. At the end of December 2009, a committee of experts was nominated to implement the law. This process took a long time till October 2010 when the first set of warning emails were sent out. The second round of notifications occurred at the end of February 2011 (six months after the first warning). Finally in February 2012, some expedients were sent to the court as the third strike. It has been reported that since October of 2010 the number of users that have received the first and second warning have been $1.15 \mathrm{M}$ and $100 \mathrm{~K}$ while only 340 expedients have been identified in the third phase, and 14 have been sent to the court. In September 2012, the first condemnatory sentence condemned a user to pay a fine of $150 €$ [7]. Figure 4 depicts a temporal diagram of the volume of web searches (originated in France) provided by Google Trends for the keyword "Hadopi" over which we have specified the time of the above major events as well as the collection time of pb10 and pb11 snapshots. The temporal alignment of the pronounced peaks in the search volume for Hadopi with the time of major events is a clear indicator that the French population follows this antipiracy law.

The exponential reduction in the number of warnings sent in the consecutive rounds indicates that the first two rounds were the most important since only 340 out of the $1.15 \mathrm{M}$ identified violating users in the $1^{\text {st }}$ round reached the $3^{\text {rd }}$ strike. The first two rounds took place in October 2010 and February 2011, respectively. Our pb10 snapshot was collected around April 2010 when the law was passed but still not implemented and no warning had been sent out whereas the pb11 snapshot was collected around November 2011, a few months after the $2^{\text {nd }}$ strike. Therefore the pb10 and pb11 datasets are suitable to examine the effects of the main two rounds of the Hadopi on publishers' behavior. Finally, it is important to notice that $\geq 99 \%$ of BitTorrent users are consumers (see Table I for number of consumers vs. publishers). This

\begin{tabular}{ccc} 
& pb10 & pb11 \\
\hline Avg. daily publishers-All & 487 & $367(-25 \%)$ \\
Avg. daily publishers-FR & 93 & $51(-46 \%)$ \\
Avg. daily contribution-All & $1.4 \mathrm{~K}$ & $1.3 \mathrm{~K}(-6 \%)$ \\
Avg. daily contribution-FR & 156 & $184(+18 \%)$ \\
\hline
\end{tabular}

TABLE V

COMPARISON OF THE NUMBER OF DAILY PUBLISHERS AND UPLOADED CONTENT FOR THE ENTIRE BITTORRENT (BT) ECOSYSTEM AND IN FRANCE BETWEEN PB 10 AND PB11. THE VALUE IN PARENTHESIS INDICATES THE NORMALIZED DIFFERENCE FOR EACH METRIC.

suggests that a vast majority of the $1 \mathrm{M}$ warnings were actually received by BitTorrent consumers who must have reacted by stopping their downloading activity (as demonstrated by the exponential reduction in the number of warnings sent out in the subsequent rounds). However, it is uncertain how French BitTorrent publishers ${ }^{6}$, and in particular professional publishers, reacted to the "Hadopi" law.

\section{A. Effect on Publishers Activity}

In this subsection, we investigate whether the Hadopi antipiracy law has prompted French BitTorrent (i.e. P2P) publishers to reduce or stop their activity. To tackle this issue, we examine the average daily number of publishers and uploaded files among French publishers and compare them with all BitTorrent publishers (as a reference) in snapshots pb10 and pb11. The results are summarized in Table V. The drop in the number of French publishers is roughly twice the drop among all BitTorrent publishers. However, the daily average number of uploads for the entire system dropped by $6 \%$ while that measure has increased by $18 \%$ among French publishers. This significant increase in the activity (i.e. uploads) by French publishers despite the large drop in their number is indeed surprising.

To further explore this issue, we divide the publishers into three classes of casual, regular and active publisher based on their daily average number of uploaded content as we defined in the previous section. Table VI summarizes the average daily number of French publishers from each class as well as their average daily number of uploads in pb10 and pb11. Table VI shows that $(i)$ the average daily number of casual publishers and their contributions have both dropped by $57 \%$, (ii) the average number of regular publishers has dropped by $8 \%$ but their contributions have increased by $17 \%$, (iii) finally, there are roughly two daily active publishers in both snapshots but their contribution increased by $144 \%$.

We take a closer look at each one of these trends to identify their underlying causes. First, our hypothesis is that those casual publishers $(57 \%)$ leaving the system are indeed active consumers who altruistically publish very few content. Therefore, the Hadopi law has motivated them to stop their downloading activity which in turn has led to the drop in their publishing rate as well. We verify this hypothesis by examining the distribution of the ratio of the number of

\footnotetext{
${ }^{6}$ Those BitTorrent publishers whose location of IP address is in France.
} 


\begin{tabular}{cccc}
$\mathbf{n}=$ Avg. content/day & Active $(\mathbf{n} \geq \mathbf{1 0})$ & Regular $(\mathbf{1} \leq \mathbf{n}<\mathbf{1 0})$ & Casual $(\mathbf{n}<\mathbf{1})$ \\
\hline Avg. daily publishers pb10 & 1.96 & 19.3 & 72.6 \\
Avg. daily publishers pb11 & 1.96 & 17.8 & 31.2 \\
Avg. daily publishers difference & $0(0 \%)$ & $-1.5(-8 \%)$ & $-41.4(-57 \%)$ \\
Avg. daily contribution pb10 & 34 & 66 & 56 \\
Avg. daily contribution pb11 & 83 & 77 & 24 \\
Avg. daily contribution difference & $+49(+144 \%)$ & $+11(+17 \%)$ & $-32(-57 \%)$ \\
\hline
\end{tabular}

TABLE VI

NUMBER OF PUBLISHERS AND DAILY CONTRIBUTION FOR NEXT GROUPS OF PUBLISHERS CLASSIFIED BASED ON THEIR CONTRIBUTION TO THE SYSTEM IN FRANCE FOR PB 10 AND PB 11 SNAPSHOTS. ACTIVE PUBLISHERS (N $\geq 10$ CONTENT/DAY, REGULAR PUBLISHERS $(1 \leq N<10$ CONTENT/DAY), AND CASUAL PUBLISHERS $(\mathrm{N}<1$ CONTENT/DAY $)$

downloads to uploads $(R D U)$ for casual publishers in pb10 and pb11 that is shown in Figure 5. This figure illustrates that the $R D U$ ratio among casual publishers in pb11 is roughly an order of magnitude lower than in pb10. This confirms our observation that most of the departing publishers between our two snapshots are indeed active consumers with a significant drop in their publishing activity. Note that these active consumers are likely to be regular Internet users for whom the sanctions associated with the Hadopi law is considered too costly (e.g., a fine up to $1500 €$ ).

Second, to uncover the factors that led to the significant increase in the publishing rate of active users, we take a closer look at top French publishers. We noticed that one of these publishers is scenebalance that is the most active one among all BitTorrent publishers worldwide in pb11 (as shown in Table IV). Scenebalance is a professional worldwide publisher injecting more than 100 contents per day into the BitTorrent ecosystem, most of them from France ${ }^{7}$. This raises a couple of interesting issues as follows:

(i) Since the number of French consumers has rapidly dropped, these active publishers must be targeting consumers that are outside France. To explore this issue, we have checked the published content by top five French publishers in both pb10 and pb11 snapshots. For pb10 snapshot, we found that two of the top publishers upload porn content in English, another one publishes TV series and shows in English, and the two remaining ones upload only Spanish content. In the case of pb11, we discovered a similar situation where three of the top five publishers upload only content in English, and the remaining two publish Spanish content. We extended this probe to top 20 French publishers in pb10 and pb11 and could identify only one publisher who is clearly uploading content for French consumers (e.g., French content or content with French subtitles). This investigation confirmed that major French publishers primarily target worldwide consumers.

(ii) It is then intriguing why these professional publishers operate from France while their consumers must be mostly outside France, and there is an enforced antipiracy law that could affect them. Closer examination of the top 20 French publishers revealed that more than $80 \%$ of them in both pb10 and pb11 snapshots are located at a particular hosting facility called OVH [35]. In fact, 29 of worldwide top 100 BitTorrent

\footnotetext{
${ }^{7}$ In [4], we demonstrate that usually active publishers upload their content from different IP addresses that in many cases are located in different countries.
}

publishers from pb10 and 25 of them from pb11 were hosted at $\mathrm{OVH}$. This hosting facility provides professional publishers with powerful servers to perform their intensive activity of uploading and serving (i.e. seeding) the large amount of content they make available through BitTorrent. We contacted $\mathrm{OVH}$ to gain some insight into its popularity among the professional BitTorrent publishers and learned that OVH does not proactively monitor the activities of its customers unless a violation is reported by a third party and the customer does not cease its "improper" activity [36]. Such a passive monitoring strategy is unusual as most of the hosting providers in recent years (e.g., Server Intellects [37]) have adopted strict monitoring policies to prevent the distribution of copyrighted material from their servers through $\mathrm{P} 2 \mathrm{P}$ applications. These evidences collectively suggest that the "BitTorrent-friendly" policy of OVH is much more valuable for publishers than the cost of any potential antipiracy action against publishers in France. It is important to note that professional publishers have major financial interest in publishing copyrighted material [4]. Therefore, they carefully examine any law that might affect them, take advantage of existing loopholes, and weigh the likelihood as well as the implications of any legal action against them. This suggests that even if the Hadopi law intends to targets publishers, it is much more difficult to deter at least professional publishers compared to consumers. In a nutshell, many professional publishers operate from France simply because OVH's passive monitoring policy accommodates their illegal activities.

In summary our results reveal that French antipiracy law has been quite effective on reducing the number of casual publishers in BitTorrent who were primarily consumers and the potential of receiving a fine or temporal loss of Internet connection as a result of the Hadopi law is considered costly and thus has a deterrent effect. However, the law has not succeeded in reducing the publishing rate of copyrighted material by professional publishers. These publishers seem to have most of their servers in a particular hosting provider in France primarily due to the "BitTorrent-friendly" policy of this provider. The benefits of having access to a facility that does not monitor the sharing of copyrighted material allows these businesses to comfortably operate which is clearly more valuable than the potential risk of any fine that is negligible compare to their profits. 


\section{CONCLUSIONS}

This paper presents a detailed study on how two major antipiracy actions affect the behavior of publishers in the largest BitTorrent portal who primarily publish copyrighted content. In our first case study, we focused on the impact of the Megaupload closure as a worldwide antipiracy event on BitTorrent publishers. We showed that the Megaupload closure triggered an immediate drop in the activity of professional BitTorrent publishers that are running their own private BitTorrent portals. Furthermore, a group of casual publishers also migrated to BitTorrent most likely from Megaupload and other Cyberlockers. Our second case study revealed that the French Hadopi law was effective in reducing the number of casual BitTorrent publishers that are actually consumers. However, it did not have any impact on the activity of professional publishers from France. The concentration of very active publishers in a particular hosting facility in France suggests the popularity of this facility among BitTorrent publishers that appears to be due to its passive monitoring for copyright infringement activity. Therefore, legally savvy publishers are willing to take the chance and operate from France and are not concerned about a potentially small fine. Our findings provide a valuable insight about the effect of antipiracy actions on publishers who are engaged in online piracy and also reveal the complexity of identifying the affected group of publishers. While it is impossible to validate our findings, the collection of all supporting evidences, their temporal alignment and the dominance of target events suggest that the observed behavior among publishers are most likely driven by the corresponding antipiracy events.

\section{ACKNOWLEDGMENTS}

This work has been partially supported by the European Union through the FP7 eCOUSIN (318398) and TREND (257740) Projects and the ITEA2 TWIRL Project (Call 5-10029), the Spanish Government under the CRAMNET project (TEC2012-38362-C03-01) and eeCONTENT Project (TEC2011- 29688-C02-02), the Regional Government of Madrid through the MEDIANET project (S-2009/TIC-1468), and the National Science Foundation under Grant IIS0917381.

\section{REFERENCES}

[1] S. Alcock and R. Nelson, "Measuring the impact of the copyright amendment act on new zealand residential dsl users." in Proc. of ACM IMC'12.

[2] T. Meyer, "Graduated response in france: The clash of copyright and the internet," Journal of Information Policy, vol. 2, no. 0, 2012. [Online]. Available: http://jip.vmhost.psu.edu/ojs/index.php/jip/article/view/71

[3] B. Danaher, M. D. Smith, R. Telang, and S. Chen, "The effect of graduated response anti-piracy laws on music sales: Evidence from an event study in france," in Social Science Research Network (SSRN)., 2012. [Online]. Available: http://ssrn.com/abstract $=1989240$

[4] R. Cuevas, M. Kryczka, A. Cuevas, S. Kaune, C. Guerrero, and R. Rejaie, "Is content publishing in bittorrent altruistic or profit-driven?" in CoNEXT' '10, 2010.

[5] R. Layton and P. Watters, "Investigation into the extent of infringing content on bittorrent networks," Technical Report, 2010.

[6] E. Felten, "Census of files available via bittorrent," 2010, https:// freedom-to-tinker.com/blog/felten/census-files-available-bittorrent/.
[7] Le Figaro, "Hadopi : un premier internaute condamné." [Online]. Available: http://www.lefigaro.fr/hightech/2012/09/13/0100720120913ARTFIG00599-hadopi-un-premier-internaute-condamne.php

[8] T. Ramayah, N. H. Ahmad, L. G. Chin, and L. May-Chiun, "Testing a causal model of internet piracy behavior among university students," European Journal of Scientific Research, 2009.

[9] S. Hinduja, "Trends and patterns among online software pirates," Ethics and Inf. Technol., vol. 5, no. 1, Jun. 2003.

[10] W. D. Gunter, G. E. Higgins, and R. E. Gealt, "Pirating youth: Examining the correlates of digital music piracy among adolescents," International Journal of Cyber Criminology, vol. 4, no. 1\&2, 2010.

[11] M. W. Kampmann, "Online piracy and consumer affect : to pay or not to pay," July 2010. [Online]. Available: http://essay.utwente.n1/60470/

[12] T. Lauinger, M. Szydlowski, W. G. Onarlioglu, K., E. Kirda, and K. C., "Clickonomics: Determining the effect of anti-piracy measures for oneclick hosting," in NDSS' 13, 22013.

[13] PCMAG.com, "After megaupload, storage sites shutter services." [Online]. Available: http://www.pcmag.com/article2/0,2817,2399238, 00.asp

[14] A. Bridy, "Copyright policymaking as procedural democratic process: A discourse-theoretic perspective on acta, sopa, and pipa," in Social Science Research Network (SSRN)., 2012. [Online]. Available: http://ssrn.com/abstract=2042787

[15] C. Zhang, P. Dhungel, D. Wu, and K. Ross, "Unraveling the bittorrent ecosystem," IEEE Transactions on Parallel and Distributed Systems, 2010.

[16] http://www.alexa.com.

[17] "MaxMind- GeoIP." [Online]. Available: http://www.maxmind.com/ app/ip-location

[18] BBC, "Megaupload file-sharing site shut down." [Online]. Available: http://www.bbc.co.uk/news/technology-16642369

[19] Wikipedia, http://en.wikipedia.org/wiki/Megaupload.

[20] Envisional, "An estimate of infringing use of the internet." [Online]. Available: http://documents.envisional.com/docs/EnvisionalInternet\%5FUsage-Jan2011.pdf

[21] Z. Jelveh and K. W. Ross, "Profiting from filesharing: A measurement study of economic incentives in cyberlockers," in $P 2 P, 2012$, pp. 57-62.

[22] US Department of Justice., "Justice department charges leaders of megaupload with widespread online copyright infringement." [Online]. Available: http://www.fbi.gov/news/pressrel/press-releases/justicedepartment-charges-leaders-of-megaupload-with-widespread-onlinecopyright-infringement

[23] G. S. Becker, "Crime and punishment: An economic approach," Journal of Political Economy, vol. 76, 1968.

[24] I. Ehrlich, "Crime, punishment, and the market for offenses," Journal of Economic Perspectives, vol. 10, no. 1, 1996.

[25] French Senate, "Haute autorité pour la diffusion des oeuvres et la protection des droits sur internet," June' 2009. [Online]. Available: http://www.senat.fr/dossier-legislatif/pj107-405.html

[26] SOPA, http://www.sopastrike.com.

[27] UK Government, "Digital economy act 2010," 2010. [Online]. Available: http://www.legislation.gov.uk/ukpga/2010/24/section/1?view=plain

[28] TechWeekEurope, "Britain's anti-piracy act delayed by cost dispute," April 2012. [Online]. Available: http://www.techweekeurope.co.uk/ news/copyright-anti-piracy-act-delayed-75259

[29] Spanish Government, "Ley 2/2011,de economía sostenible," March 2011. [Online]. Available: http://www.boe.es/boe/dias/2011/03/05/pdfs/ BOE-A-2011-4117.pdf

[30] Intereconomia. [Online]. Available: http://www.intereconomia. com/noticias-gaceta/cultura/sgae- $\% \mathrm{E} 2 \% 80 \% 9 \mathrm{C}$-valoracion-todos-lossectores-culturales-negativa\%E2\%80\%9D-20120724

[31] Parliamentary Council Office of New Zeland, "Copyright (infringing file sharing) amendment act 2011," April 2011. [Online]. Available: http:// www.legislation.govt.nz/act/public/2011/0011/latest/DLM2764312.html

[32] Global Censorship Chokepoints, 2011, http://globalchokepoints.org/ countries/south-korea.

[33] Internet Initiative Japan Inc, "Traffic shifting away from $\mathrm{p} 2 \mathrm{p}$ file sharing to web services," Internet Infrastructure Review, vol. 8, no. 0, pp. 25-30, August 2010.

[34] http://www.netflix.com.

[35] http://www.ovh.com.

[36] "Ovh's terms of service," http://www.ovh.co.uk/support/termsofservice/.

[37] "Server Intellect Use Policy," http://www.serverintellect.com/terms/aup. aspx. 